\title{
Endoilluminator phototoxic maculopathy associated with combined ICG-assisted epiretinal membrane and internal limiting membrane peeling
}

This article was published in the following Dove Press journal:

Clinical Ophthalmology

9 December 2014

Number of times this article has been viewed

\section{Yoshihiro Yonekawa \\ Ashkan M Abbey \\ Ankoor R Shah \\ Benjamin J Thomas \\ Antonio Capone Jr}

Associated Retinal Consultants, Department of Ophthalmology, William Beaumont Hospital, Royal

Oak, MI, USA
Correspondence: Ashkan M Abbey Associated Retinal Consultants, Department of Ophthalmology, William Beaumont Hospital, 3535 West

Thirteen Mile Road, Suite 344, Royal

Oak, MI 48073, USA

Tel +I 2482882280

Fax + I 2482885644

Email ashkanabbey@post.harvard.edu

\begin{abstract}
Phototoxic maculopathy caused by endoillumination during macular surgery is uncommon. Previously identified risk factors have included intensity of the light source, proximity to the retinal surface, and length of exposure. In the era of indocyanine green (ICG)assisted internal limiting membrane (ILM) peeling, the use of ICG, and the technique of ILM peeling may both contribute to subsequent phototoxic maculopathy. We present cases of routine chromovitrectomy who developed phototoxic maculopathy in the precise discrete distribution of the ILM rhexes, and discuss potential mechanisms and implications.
\end{abstract}

Keywords: ILM peeling, indocyanine green, vitrectomy, ERM

\section{Introduction}

Visualization of near-transparent tissues during vitreoretinal surgery is greatly enhanced with endoillumination. However, the trade-off to maximizing visualization during macular surgery is the potential for macular phototoxicity if the intensity or duration of exposure is past a certain threshold. Phototoxic outer retinopathy from endoillumination has been well documented for decades.

Recent advances in vitreoretinal surgical techniques have new implications for phototoxic maculopathy. First, the advent of smaller gauge instrumentation has led to a reduction in light pipe diameter and a consequent decrease in illumination, which requires the surgeon to compensate by increasing light intensity. ${ }^{1}$ Second, internal limiting membrane (ILM) peeling has been finding an increasing number of indications. It assures the complete removal of epiretinal membranes and tangential traction, but may produce iatrogenic retinal damage. ${ }^{2,3}$ Third, ILM peeling is commonly assisted with indocyanine green (ICG) staining in the United States. Although the clinical experience with ICG has been mostly benign, it has been implicated in many animal and in vitro models to confer a risk for phototoxicity due to its photosensitizing properties. ${ }^{4}$

We present two cases of ICG-assisted ILM peeling that resulted in geographic pigmentary maculopathies precisely underlying the areas where the ILM rhexes were performed. We hypothesize that surgical factors associated with ILM peeling and intravitreal ICG may have contributed to these well-circumscribed lesions.

\section{Case I}

A 73-year-old man with a history of neovascular age-related macular degeneration in the eye developed an epiretinal membrane (ERM) with tractional macular thickening (Figure 1A and B). Visual acuity was 20/50 with metamorphopsia. The patient underwent a standard three-port 25-gauge pars plana vitrectomy with ERM/ILM peeling. 


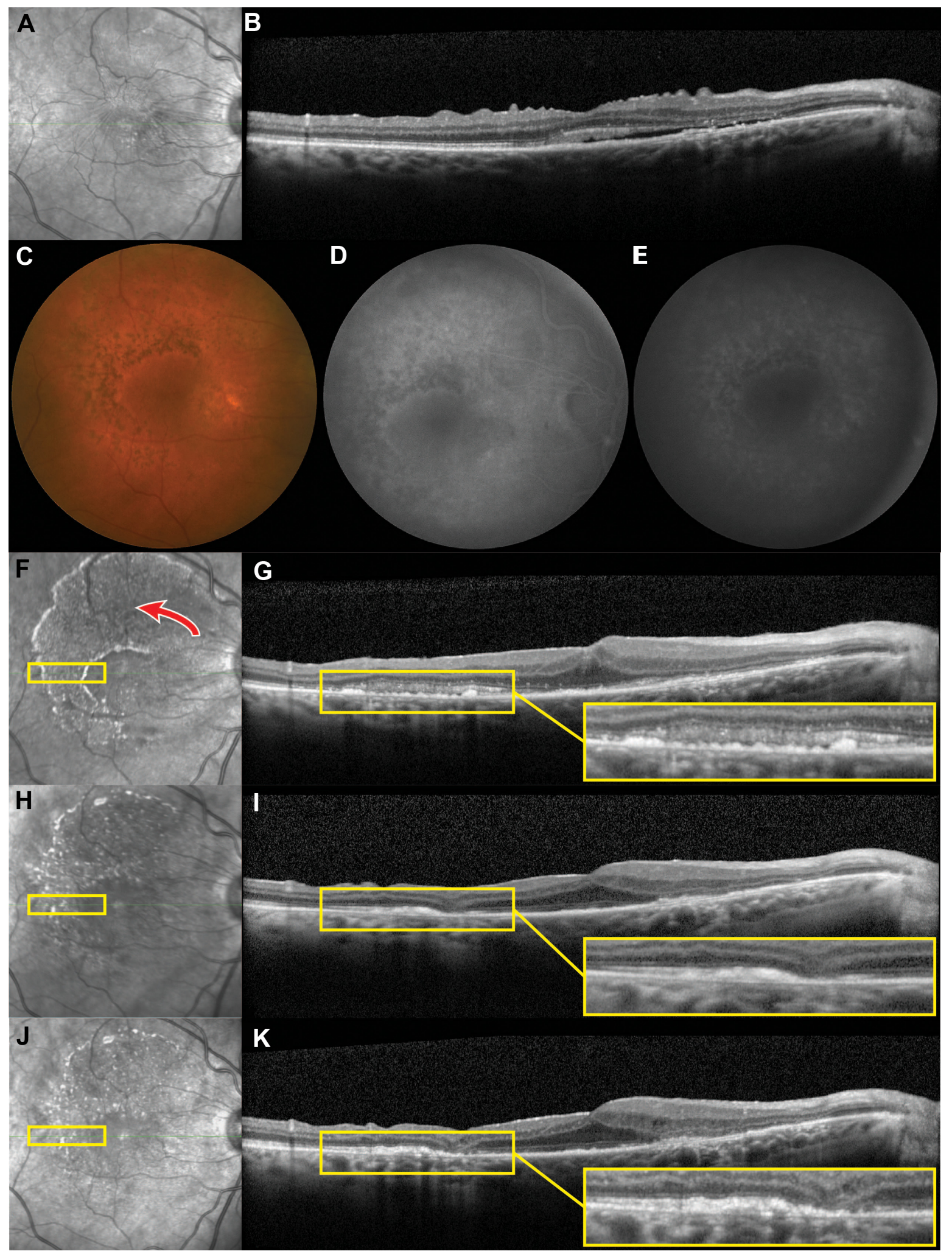

Figure I Case I.

Notes: Infrared imaging demonstrates retinal striations from an ERM (A). SD-OCT shows an ERM with puckering of the inner retina. There is thickening of the retina and a sliver of subretinal fluid (B). Four weeks after vitrectomy with ERM and indocyanine green-assisted ILM peeling, postoperative pigmentary changes in the configuration of the ILM rhexis are shown on color fundus photography $(\mathbf{C})$, and noted as window defects on early (D) and late (E) fluorescein angiography frames. Infrared imaging shows the geographic shape of the retinopathy, with the direction of the ILM peeling indicated (red arrow) (F). SD-OCT demonstrates disruption of the ellipsoid zone with mottling of the retinal pigment epithelium in the areas of pigmentary change (inset) $(\mathbf{G})$. During the 6-month $(\mathbf{H}, \mathbf{I})$ and 9-month $(\mathbf{J}, \mathbf{K})$ postoperative visits, the affected areas display increasing outer retinal atrophy (insets).

Abbreviations: ERM, epiretinal membrane; ILM, internal limiting membrane; SD-OCT, spectral-domain optical coherence tomography. 
Approximately $0.1 \mathrm{~mL}$ of ICG $0.2 \%$ is applied under fluid before being immediately removed. ICG is reapplied once after ERM peeling to stain residual ILM. The ILM rhexis is initiated with a vertical incision employing microvitreoretinal blade in the papillomacular bundle, whereupon the ILM is grasped with Eckardt forceps and carried forward in a counterclockwise fashion. The ILM is swiftly removed off the fovea at the end of the peel. The light pipe is maintained approximately $10 \mathrm{~mm}$ away from the retinal surface in the midvitreous, and total operative time on the macula is approximately 10-15 minutes.

On the 1-month postoperative visit, a discrete fan-shaped perifoveal pigmentary alteration was apparent, conforming to the sweep of the ILM rhexis (Figure 1C). Fluorescein angiography showed corresponding window defects (Figure 1D and E), and spectral-domain optical coherence tomography (SD-OCT) demonstrated outer retinal changes with disruption of the ellipsoid zone, with underlying retinal pigment epithelial (RPE) mottling (Figure $1 \mathrm{~F}$ and $\mathrm{G}$ ). Over the next 8 months, the RPE/ outer retinal architecture atrophied (Figure $1 \mathrm{H}-\mathrm{K}$ ). Final visual acuity improved to 20/40 with resolution of metamorphopsia, but with a residual inferior scotoma.

\section{Case 2}

A 67-year-old man with a history of diabetic macular edema developed a concomitant ERM (Figure 2A and B). Visual acuity was 20/60 with no metamorphopsia. He underwent a standard three-port 25-gauge pars plana vitrectomy with sequential ICGassisted ERM and ILM peeling, in the same fashion as described above. This patient also received $2 \mathrm{mg}$ of triamcinolone at the end of the case. At the 1-month postoperative visit, we noted a similar fan-shaped pigmentary alteration that was evident on infrared imaging (Figure $2 \mathrm{C}$ ). In the areas of outer retinal disturbances, SD-OCT showed focal discontinuities of the external limiting membrane, outer nuclear layer, and ellipsoid zone, as well as underlying RPE mottling (Figure 2D), which had improved on the 4-month postoperative visit (Figure 2E and F). Fundus photography and autofluorescence (AF) were obtained on the final visit, which showed scattered foci of mixed hyperand hypo-AF (Figure $2 \mathrm{G}$ and $\mathrm{H}$ ). Final visual acuity improved to $20 / 30$, with no scotoma.

\section{Discussion}

The phototoxic effects of endoillumination have been recognized since the initial years of vitrectomy. ${ }^{5-8}$ Light toxicity occurs through two mechanisms: photothermal damage, caused by increases in kinetic energy and subsequent temperature rise, leading to loss of molecular structures, and photochemical damage, resulting from free radical damage to photoreceptor and RPE cell membranes. ${ }^{9}$ The risk of phototoxicity increases with longer exposure time, higher light intensity, and shorter wavelength. ${ }^{8}$ Early studies showed that exposure times as short as 10 minutes may result in retinal alternations. ${ }^{5}$ The relative risk of phototoxicity from operating microscopes is small, because the tissues anterior to the retina can shield the macula from damage-inducing short-wavelengths by absorbing and reflecting photons. ${ }^{9,10}$ However, a vitrectomized eye with the light source in immediate proximity to the retina does not have interfering tissues. Macular surgeries are therefore the most likely to cause phototoxic maculopathies. ${ }^{6}$

The maculopathy is most clinically evident several days after the surgery. An initial whitening of the outer retina progresses to RPE hypopigmentation and window defects on angiography. ${ }^{8}$ Studies prior to SD-OCT indicated that the fundus appearance can be deceiving and may not necessarily correlate with visual acuity. ${ }^{11}$ However, SD-OCT is able to assess the extent and location of outer retinal disruption as we demonstrate in this report, which likely correlates with visual outcomes. Long-term follow-up of patients have shown that the course of phototoxic maculopathies vary: some improve, while some worsen. ${ }^{11}$ SD-OCT for Case 1 showed progressive outer retinal atrophy, resulting in a corresponding scotoma. On the other hand, Case 2 demonstrated an improvement in outer retinal architecture, and this patient did not experience field defects. AF for Case 2 also showed scattered foci of hyper- and hypo-AF. Drawing parallels to our experience with geographic atrophy in age-related macular degeneration, ${ }^{12}$ the hypo-AF represents nonviable RPE, while hyper-AF likely represents a hypermetabolic state that may precede atrophic changes. AF was not obtained for Case 1 , but it would have likely shown more hypo-AF lesions that correspond to areas of atrophy and the visual field defect.

Awareness of light toxicity has changed the ophthalmic surgeon's practice patterns, and we now make frequent adjustments to minimize the light burden during surgeries. Endoillumination phototoxicity has recently regained attention in light of chromovitrectomy's popularization. In the United States, ICG is a commonly used vital dye. Studies, mostly in animal and in vitro models, have shown that ICG may have retinotoxic effects with prolonged exposure and high concentrations. ${ }^{4}$ Clinical experiences have been mixed though, with some studies that demonstrate potential toxicity, ${ }^{13-15}$ while others do not. ${ }^{16,17}$ Overall, efficient use of the proper concentration appears to have no deleterious effects.

The present cases are unique from previously reported phototoxic maculopathies, because the discrete lesions followed the precise outline of the ILM rhexes. ILM peeling is finding an 




Figure 2 Case 2.

Notes: Infrared imaging demonstrates retinal striations from an ERM (A). SD-OCT shows an ERM with thickening of the retina and mild intraretinal cystic spaces (B). Seven weeks after vitrectomy with ERM and indocyanine green-assisted ILM peeling, infrared imaging shows a geographically shaped maculopathy, with the direction of the ILM rhexis indicated (red arrow) (C). SD-OCT demonstrates focal disruption of the outer retina with mottling of the retinal pigment epithelium (inset) (D). At the 4-month postoperative visit, the outer retinal changes have improved with regeneration of the external limiting membrane (F, arrow heads) and ellipsoid zone (E, F). Fundus color photography shows the corresponding pigmentary changes, and microvascular abnormalities consistent with preexisting history of diabetic retinopathy (G). Fundus AF shows scattered foci of hyper- and hypo-AF $(\mathbf{H})$.

Abbreviations: AF, autofluorescence; ERM, epiretinal membrane; ILM, internal limiting membrane; SD-OCT, spectral-domain optical coherence tomography. 
increasing number of indications, but the potential drawbacks are not well studied. ILM peeling may represent a risk factor for phototoxicity. The maculopathy in our cases were broadest in the papillomacular bundle where more time was spent to create the initial edge of ILM. Additionally, the intensity of light is greatest at the center of the conical projection of the light source. Thus, as time of light exposure decreases (outside the papillomacular bundle), only areas with the greatest light intensity would continue to demonstrate phototoxicity, which would produce the smaller tail. Mechanical retinal damage from ILM forceps grasps is well known, but such a large contiguous area would be unlikely to have been caused by focal forceps trauma. Furthermore, grasp sites are reported to cause inner retinal alternation, ${ }^{3}$ as opposed to phototoxicity, which predominantly causes outer retinal damage. ${ }^{18}$ Direct ICG toxicity was also unlikely because of the sharp demarcation of the maculopathy; ICG is applied diffusely to stain a large portion of the macula. However, ICG may have theoretically potentiated the light-induced maculopathy through its photosensitizing properties to some degree, ${ }^{19}$ due to the minimal overlap of the xenon endoillumination emission spectrum and ICG absorbance. ${ }^{20}$ Although the clinical significance is uncertain, several cell culture studies have shown that light and ICG toxicities may be synergistic..$^{21,22}$

These cases demonstrate that the currently popularized surgical technique of ILM peeling may pose a risk for phototoxic maculopathy, especially during ICG chromovitrectomy. Therefore, when manipulating ILM, particularly with sequential ERM/ILM peeling, we recommend efficient surgery with attention to the distance between the macula and the endoilluminator. The ILM rhexis should be fashioned to set up the ILM to peel over the fovea for removal in the most efficient fashion possible.

\section{Acknowledgments}

Yoshihiro Yonekawa is partially funded by the Heed Ophthalmic Foundation. The Foundation had no role in the design or conduct of the study. This manuscript has not been previously presented or submitted for publication.

\section{Disclosure}

The authors report no conflicts of interest in this work.

\section{References}

1. Charles S. Illumination and phototoxicity issues in vitreoretinal surgery. Retina. 2008;28(1):1-4.

2. Ahn SJ, Ahn J, Woo SJ, Park KH. Photoreceptor change and visual outcome after idiopathic epiretinal membrane removal with or without additional internal limiting membrane peeling. Retina. 2014;34(1):172-181.
3. Diaz RI, Randolph JC, Sigler EJ, Calzada JI. Intraoperative grasp site correlation with morphologic changes in retinal nerve fiber layer after internal limiting membrane peeling. Ophthalmic Surg Lasers Imaging Retina. 2014;45(1):45-49.

4. Rodrigues EB, Meyer CH, Mennel S, Farah ME. Mechanisms of intravitreal toxicity of indocyanine green dye: implications for chromovitrectomy. Retina. 2007;27(7):958-970.

5. Fuller D, Machemer R, Knighton RW. Retinal damage produced by intraocular fiber optic light. Am J Ophthalmol. 1978;85(4): 519-537.

6. Kuhn F, Morris R, Massey M. Photic retinal injury from endoillumination during vitrectomy. Am J Ophthalmol. 1991;111(1):42-46.

7. Poliner LS, Tornambe PE. Retinal pigment epitheliopathy after macular hole surgery. Ophthalmology. 1992;99(11):1671-1677.

8. Michels M, Lewis H, Abrams GW, Han DP, Mieler WF, Neitz J. Macular phototoxicity caused by fiberoptic endoillumination during pars plana vitrectomy. Am J Ophthalmol. 1992;114(3):287-296.

9. Youssef PN, Sheibani N, Albert DM. Retinal light toxicity. Eye (Lond). 2011;25(1):1-14.

10. Ham WT, Ruffolo JJ, Mueller HA, Guerry D. The nature of retinal radiation damage: dependence on wavelength, power level and exposure time. Vision Res. 1980;20(12):1105-1111.

11. Postel EA, Pulido JS, Byrnes GA, et al. Long-term follow-up of iatrogenic phototoxicity. Arch Ophthalmol. 1998;116(6):753-757.

12. Yonekawa Y, Kim IK. Clinical characteristics and current treatment of age-related macular degeneration. Cold Spring Harb Perspect Med. 2014.

13. Sheidow TG, Blinder KJ, Holekamp N, et al. Outcome results in macular hole surgery: an evaluation of internal limiting membrane peeling with and without indocyanine green. Ophthalmology. 2003;110(9): 1697-1701.

14. Ando F, Sasano K, Ohba N, Hirose H, Yasui O. Anatomic and visual outcomes after indocyanine green-assisted peeling of the retinal internal limiting membrane in idiopathic macular hole surgery. Am J Ophthalmol. 2004;137(4):609-614.

15. Querques G, Prascina F, Iaculli C, Noci ND. Retinal toxicity of indocyanine green. Int Ophthalmol. 2008;28(2):115-118.

16. Slaughter K, Lee IL. Macular hole surgery with and without indocyanine green assistance. Eye (Lond). 2004;18(4):376-378.

17. Hillenkamp J, Saikia P, Gora F, et al. Macular function and morphology after peeling of idiopathic epiretinal membrane with and without the assistance of indocyanine green. Br J Ophthalmol. 2005;89(4): 437-443.

18. Irvine AR, Wood I, Morris BW. Retinal damage from the illumination of the operating microscope. An experimental study in pseudophakic monkeys. Arch Ophthalmol. 1984;102(9):1358-1365.

19. Haritoglou C, Gandorfer A, Schaumberger M, Tadayoni R, Gandorfer A, Kampik A. Light-absorbing properties and osmolarity of indocyaninegreen depending on concentration and solvent medium. Invest Ophthalmol Vis Sci. 2003;44(6):2722-2729.

20. Costa Ede P, Rodrigues EB, Farah ME, et al. Vital dyes and light sources for chromovitrectomy: comparative assessment of osmolarity, $\mathrm{pH}$, and spectrophotometry. Invest Ophthalmol Vis Sci. 2009;50(1): $385-391$.

21. Sato T, Ito M, Ishida M, Karasawa Y. Phototoxicity of indocyanine green under continuous fluorescent lamp illumination and its prevention by blocking red light on cultured Müller cells. Invest Ophthalmol Vis Sci. 2010;51(8):4337-4345.

22. Takayama K, Sato T, Karasawa Y, Sato S, Ito M, Takeuchi M. Phototoxicity of indocyanine green and Brilliant Blue $\mathrm{G}$ under continuous fluorescent illumination on cultured human retinal pigment epithelial cells. Invest Ophthalmol Vis Sci. 2012;53(11):7389-7394. 


\section{Publish your work in this journal}

Clinical Ophthalmology is an international, peer-reviewed journal covering all subspecialties within ophthalmology. Key topics include: Optometry; Visual science; Pharmacology and drug therapy in eye diseases; Basic Sciences; Primary and Secondary eye care; Patient Safety and Quality of Care Improvements. This journal is indexed on

Submit your manuscript here: http://www.dovepress.com/clinical-ophthalmology-journal
PubMed Central and CAS, and is the official journal of The Society of Clinical Ophthalmology (SCO). The manuscript management system is completely online and includes a very quick and fair peer-review system, which is all easy to use. Visit http://www.dovepress.com/ testimonials.php to read real quotes from published authors. 